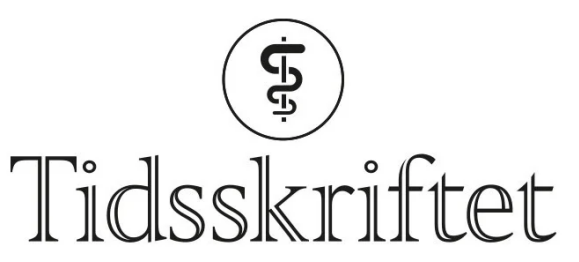

DEN NORSKE LEGEFORENING

\title{
Gynekologiske fistler etter kirurgi eller strålebehandling
}

ORIGINALARTIKKEL

\section{NAVNEET KAUR VIRDEE}

Klinisk institutt 2

Universitetet i Bergen

Hun har bidratt med datainnsamling, analyse, litteratursøk, datatolkning, utarbeiding og godkjenning av manuskriptet.

Navneet Kaur Virdee er lege i spesialisering del 1 i Helse Førde.

Forfatteren har fylt ut ICMJE-skjemaet og oppgir ingen interessekonflikter.

\section{EMILIE K. RINGDAL}

Klinisk institutt 2

Universitetet i Bergen

Hun har bidratt med datainnsamling, analyse, litteraturs $ø$, datatolkning, utarbeiding og godkjenning av manuskriptet.

Emilie K. Ringdal er lege i spesialisering del 1 ved Haukeland universitetssjukehus.

Forfatteren har fylt ut ICMJE-skjemaet og oppgir ingen interessekonflikter.

\section{HEIDI THORNHILL}

Kvinneklinikken

Haukeland Universitetssjukehus

Hun har bidratt med idé, utforming og design, datainnsamling og -tolkning, utarbeiding og godkjenning av manuskriptet.

Heidi Thornhill er spesialist i fødselshjelp og kvinnesykdommer og overlege.

Forfatteren har fylt ut ICMJE-skjemaet og oppgir ingen interessekonflikter.

\section{TORVID KISERUD}

Kvinneklinikken

Haukeland Universitetssjukehus

og

Klinisk institutt 2

Universitetet i Bergen

Han har bidratt med idé, utforming og design, analyse, litteratursøk, datatolkning, utarbeiding og godkjenning av manuskriptet.

Torvid Kiserud er spesialist i fødselshjelp og kvinnesykdommer og professor emeritus.

Forfatteren har fylt ut ICMJE-skjemaet og oppgir ingen interessekonflikter.

\section{JONE TROVIK}

jone.trovik@helse-bergen.no

Kvinneklinikken

Haukeland Universitetssjukehus 
Hun har bidratt med idé, utforming og design, datainnsamling, analyse, litteratursøk, datatolkning, utarbeiding og godkjenning av manuskriptet.

Jone Trovik er spesialist i fødselshjelp og kvinnesykdommer, overlege og professor.

Forfatteren har fylt ut ICMJE-skjemaet og oppgir ingen interessekonflikter.

\section{BAKGRUNN}

Gynekologiske fistler forårsaker urin- og/eller fekalinkontinens. Haukeland universitetssjukehus har fortløpende registrert behandlingskarakteristika for gynekologiske fistler, fra 2012 med funksjon som nasjonal behandlingstjeneste for gynekologiske fistler. Denne studien beskriver karakteristika og behandlingsutfall for gynekologiske fistler forårsaket av kirurgi og/eller strålebehandling.

MATERIALE OG METODE

Vi har utført en retrospektiv kohortstudie av kvinner som ble behandlet ved Kvinneklinikken, Haukeland universitetssjukehus 1995-2019 for gynekologiske fistler forårsaket av kirurgi eller strålebehandling.

\section{RESULTATER}

Kirurgi eller strålebehandling var årsak til gynekologiske fistler hos 182 av 411 kvinner. 163 av disse samtykket til studien, 124/163 (76\%) med fistel etter kirurgi og 39/163 (24\%) etter strålebehandling. Fistler etter kirurgi var hovedsakelig urogenitale ( $91 / 124 ; 73 \%)$ og oftest forårsaket av hysterektomi $(n=71)$ eller urininkontinensprosedyre $(n=11)$. Fistler etter strålebehandling var hovedsakelig enterogenitale $(34 / 39 ; 87 \%)$, med rektumcancer $(n=22)$ og cervixcancer $(\mathrm{n}=11)$ som hyppigste kreftformer. Hovedprosedyren var vaginal fistelplastikk, som ble utført hos 100/124 (81\%) kvinner med fistel etter kirurgi og 7/39 (18\%) med fistel etter stråling. Kateterdrenasje eller stomi alene ga tilheling hos 14/163 (9\%) av alle pasientene. Totalt 117/124 (94\%) av kvinnene med fistel etter kirurgi oppnådde tilheling, mot 10/39 (26\%) av kvinnene med fistel etter strålebehandling. 28/39 (72 \%) av disse fikk permanent uro-/enterostomi.

\section{FORTOLKNING}

Gynekologiske fistler forårsaket av kirurgi har god tilhelingsrate, mens fistler etter strålebehandling oftere forblir permanente.

\section{HOVEDFUNN}

I perioden 1995-2019 økte det totale antallet pasienter og andelen pasienter henvist fra andre helseregioner for behandling av gynekologiske fistler ved Haukeland universitetssjukehus.

Gynekologisk fistel etter kirurgi affiserte oftest urinveier, og hysterektomi eller stressinkontinensoperasjon var vanligste årsak.

Gynekologisk fistel etter strålebehandling forekom oftest etter behandling for rektumeller cervixcancer og affiserte oftest tarm.

De kirurgiske fistlene kunne oftest opereres med vaginal fistelplastikk og hadde svært god prognose ( $94 \%$ tilheling), mens fistel etter strålebehandling tilhelte sjeldnere $(26 \%)$ og forble ofte med permanent uro- eller enterostomi (72\%). 
Gynekologiske fistler med kommunikasjon mellom genitalia (livmor, skjede eller perineum) og urinveier (urogenitale fistler) eller med tarm (enterogenitale fistler), forårsaker lekkasje av urin eller avføring/luft og gir betydelig redusert livskvalitet (11). Globalt er det fistler som fødselskomplikasjon (obstetrisk fistel) som dominerer. Dette forekommer etter opptil 124/100 ooo fødsler i utviklingsland (르) og 16/100 ooo i land med god fødselsomsorg (3). I industrialiserte land har gynekologiske fistler en årlig insidens på 6/10 ooo (4), hovedsakelig som komplikasjon ved bekkenkirurgi eller strålebehandling (5).

Gynekologiske fistler er gjerne beskrevet i organspesifikke kohortstudier, f.eks. urogenitale fistler behandlet ved urologisk avdeling (므) eller enterogenitale fistler ved gastrokirurgisk avdeling (7.). I studier fra gynekologiske avdelinger er det beskrevet obstetriske fistler (3), mens få publikasjoner omhandler gynekologisk behandling av fistler av andre årsaker.

Ved Kvinneklinikken på Haukeland universitetssjukehus har behandling av gynekologiske fistler blitt systematisk registrert og fulgt opp siden 1995 (ㅁ), og i 2012 ble avdelingen oppnevnt som nasjonal behandlingstjeneste for gynekologiske fistler. Senteret har tidligere rapportert om fistler behandlet i perioden 1995-2005, dvs. før formell nasjonal funksjon ( $\underline{8})$.

Kirurgi i bukhule og bekken har endret seg betydelig de siste tiårene, med økende andel laparoskopi (inkludert robotkirurgi) som erstatning for laparotomi $(9, \underline{10})$ samt bruk av nett og slynger ved urininkontinens og genitalprolaps $(\underline{11}, \underline{12})$, noe som kan påvirke risikoen og mønsteret for fistelutvikling. Strålebehandling er fortsatt en aktuell behandlingsform, særlig ved anorektal og cervikal kreft (13).

I Norge har mer enn 1600 kvinner (o,6\% av den kvinnelige befolkningen) vært innlagt på sykehus tre eller flere ganger med fisteldiagnose i henhold til Norsk pasientregister (NPR) (4). Data fra dette registeret reflekterer antall kvinner som mottar kirurgisk behandling for gynekologisk fistel, men kan ikke si noe om årsak eller behandlingsutfall.

Med denne studien ønsket vi å beskrive kliniske karakteristika ved og behandlingsresultater for gynekologiske fistler forårsaket av kirurgi eller strålebehandling ved gjennomgang av en 25-årskohort fra en avdeling som siden 2012 har vært et nasjonalt behandlingssenter.

\section{Materiale og metode}

Denne studien inkluderte en sykehuskohort av kvinner som ble behandlet ved Kvinneklinikken, Haukeland universitetssjukehus 1995-2019 for gynekologisk fistel forårsaket av strålebehandling og/eller kirurgi. Data er ekstrahert fra pasientjournaler, og fra 2014 fra Register for gynekologiske fistler (Datatilsynsgodkjenning 14/oo215-2/CGN). Alle kvinner har gitt bredt, skriftlig samtykke til deltagelse i registeret. Studien er godkjent av Regional komité for medisinsk og helsefaglig forskningsetikk (REK 2015/326). Komiteen ga unntak for innhenting av samtykke fra kvinner som allerede var døde før studiestart. Deler av materialet (1995-2005) har vært omtalt tidligere ( $\underline{8})$ og er tatt med for å belyse utvikling over lang tid.

Fistler ble kategorisert som urogenitale (fra urinleder, blære eller urinrør til uterus eller vagina) eller enterogenitale (fra tarm til uterus, vagina eller perineum). Fistler som affiserte både urinveier og tarmgebet, ble kategorisert separat. Hvis kvinnen hadde mottatt strålebehandling, ble fistelen klassifisert som strålebetinget, uavhengig av eventuell forutgående eller ledsagende kirurgi.

Nivået på en fistel ble definert som avstanden fra hymenalnivå til fistelens åpning i uterus, vagina eller perineum, og størrelsen ble angitt som fistelens største tverrdiameter. 
Gynekologisk undersøkelse under generell anestesi ble supplert med cystoskopi for urogenitale fistler og direkte sondering eller oppløsning med metylenblått eller gel per rektum ved enterogenital fistel. Billeddiagnostikk (urografi/magnettomografi med kontrastforsterkning) ble brukt som tilleggsundersøkelser ved usikre funn eller mistenkt affeksjon av urinleder eller tarmsegment over rektum.

Kateter med drenasje basert på hevertprinsippet (urogenitale fistler) eller temporær enterostomi (enterogenitale fistler) ble brukt som primærbehandling dersom skaden ble påvist tidligere enn 21 dager etter antatt oppstått skade.

Vaginal fistelplastikk er avdelingens standardbehandling. Det gjøres en eksisjon av fistelen fra vaginalsiden med lagvis lukking av blære-/tarmvegg, vesikovaginal-/rektovaginalspatiet og vaginalmukosa/perinealhud. Fistler fra ureter eller høyere tarmsegment enn rektum ble oftest operert via abdominal tilgang i samarbeid med urolog eller gastrokirurg.

Ved urogenital fistel fikk kvinnen kateterdrenasje frem til postoperativ kontroll etter 14 dager, mens enterogenital fistel ble kontrollert 2-3 måneder etter primærbehandling. Ved fistel etter strålebehandling ble alltid enterostomi anlagt før eventuell fistelkirurgi, og denne ble reversert dersom etterkontroll bekreftet tilheling (14.). Kvinnene ble fulgt med etterkontroller til fistelen var bekreftet lukket eller man ikke anså å ha ytterligere fistelrettet behandling å tilby.

STATISTISK ANALYSE

Alle individuelle data ble anonymisert før registrering. Statistiske analyser ble utført med programmet SPSS versjon 21 (IBM Corporation, Armonk, NY, USA). Kontinuerlige data var ikke normalfordelte, og er presentert som median. Spredning er angitt som interkvartilbredde (IKB) og sammenlignet ved ikke-parametrisk test (Mann-Whitneys Utest). Kategoriske variabler ble sammenlignet ved Pearsons khikvadrattest eller Fishers eksakte test dersom antatt $<5$ i enkeltceller. Statistisk signifikans ble angitt som tosidig pverdi $<0,05$.

\section{Resultater}

Av totalt 411 kvinner diagnostisert med gynekologisk fistel i tidsrommet 1995-2019 hadde 182 kvinner en fistel forårsaket av strålebehandling eller kirurgi. 163/182 (90 \%) av disse samtykket til deltagelse i studien (figur 1). Totalt hadde 8o/163 kvinner (49\%) vært behandlet for kreft. I alt 94 kvinner hadde urogenital fistel, 62 enterogenital fistel, mens 7 hadde fistel som omfattet både urinveier og tarm. 


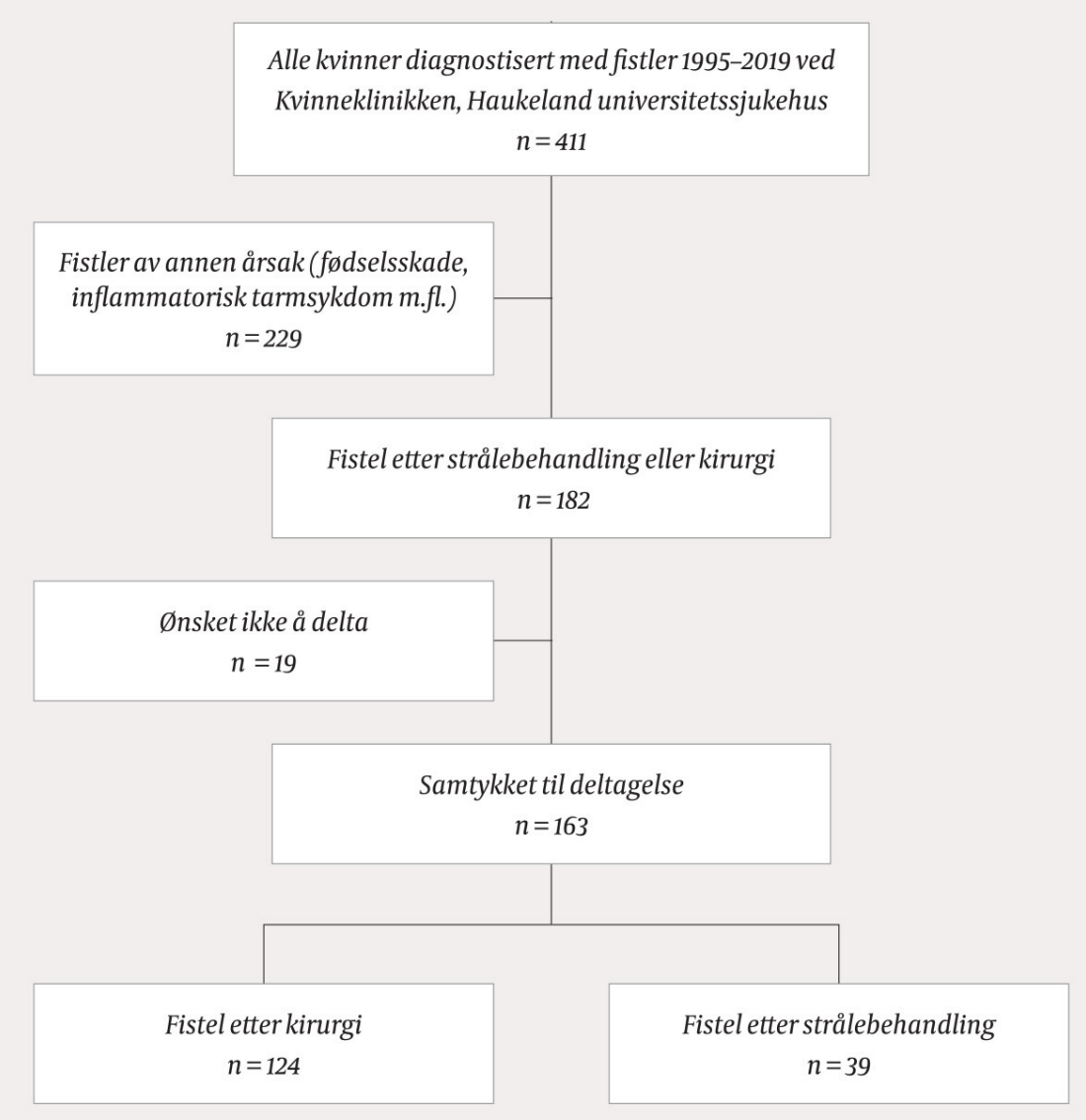

Figur 1 Gynekologiske fistler forårsaket av kirurgi og/eller strålebehandling behandlet ved Kvinneklinikken, Haukeland universitetssjukehus 1995-2019.

UTVIKLING OVER TID

Antall kvinner behandlet ved avdelingen økte hver femårsperiode i løpet av de undersøkte 25 årene (tabell 1). Andelen som ble henvist fra andre helseregioner enn Helse Vest, økte signifikant, fra 1/12 (8\%) av pasientene i tidsrommet 1995-99 til 89/154 (58\%) i tiden 2015-19. Denne andelen var størst for kvinner med fistler forårsaket av kirurgi. Totalt 35/46 (76\%) av pasientene var henvist fra andre regioner den siste femårsperioden.

\section{Tabell 1}

Kvinner diagnostisert med gynekologisk fistel $(n=411)$ i tidsrommet 1995-2019 ved Kvinneklinikken, Haukeland universitetssjukehus (fra 2012: Nasjonal behandlingstjeneste for gynekologiske fistler). Andel kvinner per femårsperiode som tilhørte Helse Vest er sammenlignet med kvinner henvist fra andre regioner.

\begin{tabular}{|lrrrrrrr|}
\hline $\begin{array}{l}\text { Helseregion, } \\
\mathrm{n}(\%)\end{array}$ & $1995-99$ & 2000-04 & 2005-09 & 2010-14 & 2015-19 & P-verdi $^{1}$ \\
\hline Helse Vest & $11(92)$ & $46(90)$ & $68(75)$ & $70(68)$ & $65(42)$ & $<0,001$ \\
\hline $\begin{array}{l}\text { Andre } \\
\text { regioner }\end{array}$ & $1(8)$ & $5(10)$ & $23(25)$ & $33(32)$ & $89(58)$ & \\
\hline
\end{tabular}

${ }^{1}$ Khikvadrattest 
Kirurgi var årsak til fistel hos 124/163 kvinner (76\%) (tabell 2). Fistel etter kirurgi var urogenitale hos 91/124 (73\%) og forårsaket av hysterektomi hos 71/124 (57\%) (hvorav 6 vaginalt og 12 laparoskopisk), eller etter urininkontinensinngrep med tensjonsfri vaginaltape (TVT) hos 11/124 (9\%). Hos 24/33 (72\%) av kvinner med enterogenital fistel var tarminngrep årsaken. Av kvinnene med fistel etter kirurgi var 41/124 (33\%) operert på grunn av kreftsykdom, hvorav 20 grunnet kolorektalkreft. Kvinner med fistel etter kirurgi var signifikant yngre enn kvinner med fistel etter strålebehandling, og det gikk signifikant kortere tid fra skaden til symptomer enn ved fistel etter strålebehandling (tabell 2).

\section{Tabell 2}

Kliniske karakteristika for 163 kvinner med gynekologisk fistel etter kirurgi eller strålebehandling behandlet ved Kvinneklinikken, Haukeland universitetssjukehus i perioden 1995-2019. Alle verdier er median (interkvartilbredde).

\begin{tabular}{|lrrc|}
\hline Variabel & $\begin{array}{l}\text { Fistel etter } \\
\text { kirurgi } \\
\mathrm{n}=124\end{array}$ & $\begin{array}{l}\text { Fistel etter } \\
\text { strålebehandling } \\
\mathrm{n}=39\end{array}$ & P-verdi $^{1}$ \\
\hline Alder ved diagnose (år) & $52,5(17)$ & $60,0(23)$ & 0,017 \\
\hline Tid fra skade til symptom (uker) & $1(4)$ & $14(206)$ & $<0,001$ \\
\hline $\begin{array}{l}\text { Tid fra symptom til diagnose } \\
\text { (uker) }\end{array}$ & $17(57)$ & $60(40)$ & 0,002 \\
\hline $\begin{array}{l}\text { Fistelnivå (mm over } \\
\text { hymenalnivå) }\end{array}$ & $85(30)$ & $10(16)$ & $<0,001$ \\
\hline Største fisteldiameter $(\mathrm{mm})$ & $3(3)$ & & \\
\hline
\end{tabular}

${ }^{1}$ Mann-Whitneys test

\section{FISTLER ETTER STRÅLEBEHANDLING}

Av 39 kvinner med fistel etter strålebehandling hadde 29 kvinner også gjennomgått kreftkirurgi. Fistler etter strålebehandling var enterogenitale hos 34/39 (87\%).

Rektumcancer (22/39; $56 \%$ ) og cervixcancer (11/39; $28 \%$ ) var de hyppigste kreftformene. I alt $5 / 39(13 \%)$ kvinner hadde fistler som omfattet både tarm og urinveier. Fistel etter strålebehandling hadde signifikant større median diameter og var lokalisert signifikant lavere i vagina enn fistel etter kirurgi (tabell 2).

\section{RESULTAT AV FISTELBEHANDLING}

Vaginal fistelplastikk ble utført hos 107/163 (66\%) av kvinnene. Det ga tilheling hos 96/10o ( $96 \%$ ) av pasientene med fistel etter kirurgi, mot 4/7 (57\%) av dem med fistel etter strålebehandling. Abdominal fistelprosedyre ble utført hos 16/163 (9\%) av alle pasientene, hos åtte i form av reimplantasjon av ureter ved ureterovaginal fistel. Kateterdrenasje eller temporær stomi uten ytterligere fistelbehandling ga tilheling hos totalt $14 / 163$ (9\%), ti av dem med fistel etter kirurgi. Median oppfølgingstid for fistel etter kirurgi var åtte uker, mot 39 uker for fistel etter strålebehandling. Tabell 3 viser forskjell i type behandling og resultat mellom de to pasientgruppene. Det var betydelig høyere tilhelingsrate ved fistel etter kirurgi, 117/124 (94\%), mot 10/39 (26\%) ved fistel etter strålebehandling.

\section{Tabell 3}


Gynekologisk fistel etter kirurgi eller strålebehandling $(n=163)$ behandlet i perioden 19952019 ved Kvinneklinikken, Haukeland universitetssjukehus. Behandlingsvalg og resultater er sammenlignet. Median oppfølgingstid (interkvartilbredde) for fistel var 8 (18) uker etter kirurgi og 39 (102) uker etter strålebehandling. Alle verdier er antall (prosent).

\begin{tabular}{|c|c|c|c|}
\hline & $\begin{array}{l}\text { Fistel etter } \\
\text { kirurgi } \\
\mathrm{n}=\mathbf{1 2 4}\end{array}$ & $\begin{array}{l}\text { Fistel etter } \\
\text { strålebehandling } \\
\mathrm{n}=39\end{array}$ & P-verdi \\
\hline Behandlingskategori & & & $<0,001^{1}$ \\
\hline Vaginal fistelplastikk & $100(80)$ & $7(18)$ & \\
\hline Abdominal fistelkirurgi & $12(10)$ & $4(10)$ & \\
\hline Kateter/pyelostomi/enterostomi ${ }^{2}$ & $12(10)$ & $23(59)$ & \\
\hline Annen ${ }^{3} /$ ingen behandling & $0(0)$ & $5(13)$ & \\
\hline Resultat etter behandling & & & $<0,001^{4}$ \\
\hline Tilhelt fistel & $117(94)$ & $10(26)$ & \\
\hline Persisterende fistel & $7(6)$ & $29(74)$ & \\
\hline Permanent pyelostomi/enterostomi & $9(7)$ & $28(72)$ & $<0,001^{4}$ \\
\hline
\end{tabular}

\footnotetext{
${ }^{1}$ Fishers eksakte test

${ }^{2}$ Uten annen spesifikk fistelrettet kirurgi

Inkluderer ev. hyperbar behandling

${ }^{4}$ Khikvadrattest
}

\section{Diskusjon}

I denne sykehuskohorten ble det funnet store forskjeller i karakteristika og prognose for gynekologiske fistler forårsaket av kirurgi versus strålebehandling. Fistel etter strålebehandling gav senere symptomer, var større i diameter, oftere enterogenitale og tilhelte sjeldnere (26\%). Fistler etter kirurgi, derimot, hadde svært god tilhelingsrate (94\%).

Ved Haukeland universitetssjukehus, der et nasjonalt behandlingssenter ble etablert i 2012, har det vært en stadig økning både i totalt antall pasienter med gynekologiske fistler og andel pasienter henvist fra andre helseregioner. I en gjennomgang av Norsk pasientregister 2008-14 ble det funnet at en signifikant større andel av fistelinngrep, 31 \%, ble utført i Helse Vest sammenlignet med landet for øvrig (4). I siste femårsperiode (2015-19) var hele 76 \% av kvinner med fistel etter kirurgi henvist fra andre helseregioner (Helse Vest omfatter $21 \%$ av Norges befolkning). Dette tyder på at senterets tilbud er blitt ytterligere kjent og nå benyttes for hele den aktuelle pasientgruppen.

I vårt materiale var hysterektomi årsak til 57 \% av fistlene etter kirurgi og var den dominerende årsaken til urogenital fistel. Dette samsvarer med en britisk kohort fra en urologisk avdeling, der hysterektomi hadde forårsaket 159/238 (67\%) av urogenitale fistler (ㅁ). Sykehusregisterdata fra Storbritannia angir risikoen for urinveisskade ved hysterektomi til 1/788 (1,3\%), og høyere ved radikal kreftkirurgi (15). At hele 41/124 (33\%) av våre fistler etter kirurgi oppsto som ledd i kreftbehandling, støtter disse funnene. 
Det er beskrevet $ø$ kende forekomst av urinveisskader ved overgang til laparoskopisk teknikk ved hysterektomi $(\underline{10})$. I Norge er nå laparoskopi hovedmetode for hysterektomi ved godartede tilstander (9) og øker i bruk ved kreftbehandling. Vårt materiale med 6 vaginale og 12 laparoskopiske inngrep av totalt 71 hysterektomier er for lite til å konkludere på risiko for de ulike tilgangene.

Tensjonsfri vaginaltape er den vanligste operasjonen ved stressinkontinens (1ㅡ). Totalt $9 \%$ av fistler etter kirurgi i vårt materiale var forårsaket av tensjonsfri vaginaltape. I Norge ble det utført 9826 prosedyrer med tensjonsfri vaginaltape i tidsrommet 2004-08 (1ㅜㄷ), 31443 ekstrapolert til og med 2019. Det tilsvarer at 3,5 per 10 ooo kvinner operert med tensjonsfri vaginaltape er blitt behandlet for fistel ved vårt senter i den perioden.

Tid fra skade til symptomdebut var signifikant kortere ved fistel etter kirurgi, median 1 uke mot 39 uker i gruppen med fistel etter strålebehandling. Dette avspeiler nok at en kirurgisk prosedyre oftere gir umiddelbar fistel, mens strålebehandling induserer vevsendringer over tid. Hos begge grupper var det imidlertid relativt lang tid fra symptom til diagnostikk, henholdsvis 17 og 14 uker. Dette understreker at helsepersonell bør være mer oppmerksom på faren for fistelutvikling som mulig årsak ved nyoppstått urin- eller avføringslekkasje etter kirurgisk inngrep eller strålebehandling i bekkenregionen. $9 \%$ av kvinnene i vår kohort tilhelte ved kun midlertidig avlastning med kateter eller enterostomi. Dette støtter tidligere studier (17.), som viser at det er nyttig å legge inn kateter med god hevertdrenasje så snart som fistel er mistenkt. Da vil pasienten kunne unngå fistelinngrep.

Tilhelingsraten på 94\% (117/124) ved fistel etter kirurgi er meget god og lik tilhelingsraten for obstetriske fistler i Norge (93\%) (5). Vaginalplastikk har lenge vært senterets hovedmetode, og en tilhelingsrate på $97 \%$ er god, også sammenlignet med data fra Storbritannia, der man fant $86 \%$ tilheling ved transvesikal fistelplastikk ved en urologisk avdeling ( $\underline{6})$.

Fistel etter strålebehandling tilhelte hos kun $26 \%$ i vårt materiale, og $72 \%$ av disse forble med permanent uro- eller enterostomi. En britisk studie av urogenitale fistler etter strålebehandling oppnådde 53 \% tilheling (ㅁ), og i en amerikansk studie av tarmkomplikasjoner etter strålebehandling trengte $63 \%$ av dem med enterogenitale fistler permanent stomi $(\underline{18})$. Kvinner med fistel etter strålebehandling har ofte andre besværlige symptomer på stråleskade enn urin-/avføringslekkasje som følge av en eventuell fistel, som blæresmerter, dysuri og diaré (13). Det forsøkes gjerne hyperbar oksygenering som behandling av disse. Det var få pasienter i vår kohort som fikk slik behandling, og vi kan ikke vurdere i hvilken grad denne medvirker til fisteltilheling.

En studiedeltagelse på 9o \% av pasientkohorten er høy og må kunne antas å være representativ for vår behandlingskohort. Selv om pasientene ble fortløpende registrert ved senteret, er opplysninger om spesifikke kliniske detaljer og behandlingsutfall supplert i ettertid. Studien har derfor de generelle begrensningene som ligger i en retrospektiv kohortstudie.

Hovedmålet for studien var å påvise utfallet av behandlingen. Det kan ansees som en svakhet, i likhet med flere andre studier (19.), at vi mangler pasientrapporterte data om livskvalitet. For tiden gjennomgår vi derfor hva som kan være relevante kvalitetsmål å inkludere i tjenestens register for å ivareta dette aspektet ved fremtidig pasientbehandling.

\section{Konklusjon}

Ut fra våre tall kan vi konkludere med at Nasjonal behandlingstjeneste for gynekologiske fistler i økende grad blir benyttet av pasienter fra alle helseregioner, at behandlingen av gynekologiske fistler forårsaket av kirurgi er vellykket og langt bedre enn for fistler forårsaket av stråling. Fistler etter strålebehandling vil i hovedsak forbli permanente. Systematisk gjennomgang av resultater fra en nasjonal behandlingstjeneste er viktig for å gjøre tilbudet kjent og sikre likeverdig behandlingstilbud. 


\section{LITTERATUR}

1. Wilson SM, Sikkema KJ, Watt MH et al. Psychological symptoms among obstetric fistula patients compared to gynecology outpatients in Tanzania. Int J Behav Med 2015; 22: 605-13. [PubMed] [CrossRef]

2. Vangeenderhuysen C, Prual A, Ould el Joud D. Obstetric fistulae: incidence estimates for subSaharan Africa. Int J Gynaecol Obstet 2001; 73: 65-6. [PubMed][CrossRef]

3. Trovik J, Thornhill HF, Kiserud T. Incidence of obstetric fistula in Norway: a population-based prospective cohort study. Acta Obstet Gynecol Scand 2016; 95: 405-10. [PubMed][CrossRef]

4. Børseth KF, Acharya G, Kiserud T et al. Incidence of gynecological fistula and its surgical treatment: A national registry-based study. Acta Obstet Gynecol Scand 2019; 98: 1120-6. [PubMed][CrossRef]

5. Brown HW, Wang L, Bunker CH et al. Lower reproductive tract fistula repairs in inpatient US women, 1979-2006. Int Urogynecol J Pelvic Floor Dysfunct 2012; 23: 403-10. [PubMed][CrossRef]

6. Hilton P. Urogenital fistula in the UK: a personal case series managed over 25 years. BJU Int 2012; 110: 102-10. [PubMed][CrossRef]

7. Ozuner G, Hull TL, Cartmill J et al. Long-term analysis of the use of transanal rectal advancement flaps for complicated anorectal/vaginal fistulas. Dis Colon Rectum 1996; 39:10-4. [PubMed][CrossRef]

8. Egeland P, Gjøen JE, Trovik J et al. Gynekologiske fistler til urinveier og tarm. Tidsskr Nor Laegeforen 2007; 127: 417-20. [PubMed]

9. Goderstad JM, Lieng M, Busund B. Kirurgisk behandling av benigne gynekologiske lidelser. Tidsskr Nor Legeforen 2009; 129:146o-3. [PubMed][CrossRef]

10. Aarts JW, Nieboer TE, Johnson $\mathrm{N}$ et al. Surgical approach to hysterectomy for benign gynaecological disease. Cochrane Database Syst Rev 2015; 8: CDoo3677. [PubMed][CrossRef]

11. Hold $\varnothing$ B, Verelst M, Svenningsen R et al. Long-term clinical outcomes with the retropubic tensionfree vaginal tape (TVT) procedure compared to Burch colposuspension for correcting stress urinary incontinence (SUI). Int Urogynecol J Pelvic Floor Dysfunct 2017; 28: 1739-46. [PubMed][CrossRef]

12. Cohen AM, Kahn MA, Brown S. Comments to: surgical management of pelvic organ prolapse in women. Tech Coloproctol 2016; 20:327-30. [PubMed][CrossRef]

13. Viswanathan AN, Lee LJ, Eswara JR et al. Complications of pelvic radiation in patients treated for gynecologic malignancies. Cancer 2014; 120:3870-83. [PubMed][CrossRef]

14. Trovik J, Kiserud T, Reimers C et al. Gynekologiske fistler. I: Veileder i gynekologi 2015. Oslo: Den norske legeforening, 2015.

https://www.legeforeningen.no/contentassets/a5d7370e547a41989ooada248f77a6cb/gynekologiskefistler.pdf Lest 26.5.2020.

15. Hilton P, Cromwell DA. The risk of vesicovaginal and urethrovaginal fistula after hysterectomy performed in the English National Health Service-a retrospective cohort study examining patterns of care between 2000 and 2008. BJOG 2012; 119: 1447-54. [PubMed][CrossRef]

16. Dyrkorn OA, Kulseng-Hanssen S, Sandvik L. TVT compared with TVT-O and TOT: results from the Norwegian National Incontinence Registry. Int Urogynecol J Pelvic Floor Dysfunct 2010; 21: 1321-6. [PubMed][CrossRef]

17. Margolin DJ, Gonzalez RP. Retrospective analysis of traumatic bladder injury: does suprapubic catheterization alter outcome of healing? Am Surg 2004; 70: 1057-6o. [PubMed]

18. Turina M, Mulhall AM, Mahid SS et al. Frequency and surgical management of chronic complications related to pelvic radiation. Arch Surg 2008; 143: 46-52, discussion 52. [PubMed] [CrossRef]

19. Göttgens KW, Smeets RR, Stassen LP et al. The disappointing quality of published studies on operative techniques for rectovaginal fistulas: a blueprint for a prospective multi-institutional study. Dis Colon Rectum 2014; 57: 888-98. [PubMed][CrossRef]

Publisert: 7. september 2020. Tidsskr Nor Legeforen. DOI: 10.4045/tidsskr.19.0822

Mottatt 18.12.2019, første revisjon innsendt 18.4.2020, godkjent 26.5.2020.

(C) Tidsskrift for Den norske legeforening 2023. Lastet ned fra tidsskriftet.no 26. april 2023. 